\title{
Functional Abdominal Pain Syndrome
}

\author{
RAY E. CLOUSE,* EMERAN A. MAYER, ${ }^{*}$ QASIM AZIZ, $§$ DOUGLAS A. DROSSMAN," \\ DAN L. DUMITRASCU, " HUBERT MÖNNIKES, ${ }^{\#}$ and BRUCE D. NALIBOFF ${ }^{\ddagger}$ \\ *Division of Gastroenterology, Washington University, St Louis, Missouri; ${ }^{\dagger}$ University of California Los Angeles, Los Angeles, California; \\ SUniversity of Manchester, Manchester, UK; "University of North Carolina-Chapel Hill, Chapel Hill, North Carolina; "University of Medicine and \\ Pharmacy "Iuliu Hatieganu," Cluj, Romania; "Universitatsklinikum Chariter, Berlin, Germany; "†University of California Los Angeles and VA \\ GLAHS, Los Angeles, California
}

Functional abdominal pain syndrome (FAPS) differs from the other functional bowel disorders; it is less common, symptoms largely are unrelated to food intake and defecation, and it has higher comorbidity with psychiatric disorders. The etiology and pathophysiology are incompletely understood. Because FAPS likely represents a heterogenous group of disorders, peripheral neuropathic pain mechanisms, alterations in endogenous pain modulation systems, or both may be involved in any one patient. The diagnosis of FAPS is made on the basis of positive symptom criteria and a longstanding history of symptoms; in the absence of alarm symptoms, an extensive diagnostic evaluation is not required. Management is based on a therapeutic physician-patient relationship and empirical treatment algorithms using various classes of centrally acting drugs, including antidepressants and anticonvulsants. The choice, dose, and combination of drugs are influenced by psychiatric comorbidities. Psychological treatment options include psychotherapy, relaxation techniques, and hypnosis. Refractory FAPS patients may benefit from a multidisciplinary pain clinic approach.

$\mathrm{F}$ unctional abdominal pain syndrome (FAPS) represents a chronic pain disorder localized to the abdomen with features that differentiate it from other painful functional gastrointestinal disorders. Like other functional gastrointestinal disorders, symptoms are not explainable by a structural or metabolic disorder by using currently available diagnostic methods. FAPS appears highly related to alterations in endogenous pain modulation systems, including dysfunction of descending pain modulation and cortical pain modulation circuits. There is only 1 recognized diagnosis in this category of functional gastrointestinal disorders (Table 1).

Table 1. Functional Gastrointestinal Disorders

\section{Functional Abdominal Pain Syndrome}

\section{Definition}

FAPS represents a pain syndrome attributed to the abdomen that is poorly related to gut function, is associated with some loss of daily activities, and has been present for at least 6 months. The pain is constant, nearly constant, or at least frequently recurring. The principal criterion differentiating FAPS from other functional gastrointestinal disorders, such as irritable bowel syndrome (IBS) and functional dyspepsia, is the lack of symptom relationship to food intake or defecation. FAPS commonly is associated with a tendency to experience and report other somatic symptoms of discomfort, including chronic pain thought to be related to the gynecologic or urinary systems. Psychological disturbances are more likely when pain is persistent over a long period of time, is associated with chronic pain behaviors, and/or dominates the patient's life. ${ }^{1}$ In psychiatric nosology, FAPS would qualify as a somatoform pain disorder and satisfy a pain criterion toward the diagnosis of somatization disorder. $^{2}$

\section{Epidemiology}

The epidemiology of FAPS is incompletely known because of limited available data and methodological difficulties in establishing a diagnosis that can be differentiated from other more common functional gastrointestinal disorders, such as IBS and functional dyspepsia. However, it is generally considered that FAPS is a less common functional disorder than either IBS or functional dyspepsia. Reported prevalence figures in North America range from $0.5 \%$ to $2 \%$ and do not differ from those reported in other coun-

\footnotetext{
Abbreviations used in this paper: FAPS, functional abdominal pain syndrome; IBS, irritable bowel syndrome; TCAs, tricyclic antidepressants.

( $) 2006$ by the American Gastroenterological Association Institute 0016-5085/06/\$32.00 doi:10.1053/j.gastro.2005.11.062
} 
tries. ${ }^{3-5}$ The disorder is more common in women (female: male $=3: 2),{ }^{6}$ with prevalence peaking in the fourth decade of life. ${ }^{6,7}$ Patients with FAPS have high work absenteeism and health care utilization and, thus, impose a significant economic burden. $3,6,8$

\section{Diagnostic Criteria* for Functional Abdominal Pain Syndrome}

\section{Must include all of the following:}

1. Continuous or nearly continuous abdominal pain

2. No or only occasional relationship of pain with physiological events (eg, eating, defecation, or menses)

3. Some loss of daily functioning

4. The pain is not feigned (eg, malingering)

5. Insufficient symptoms to meet criteria for another functional gastrointestinal disorder that would explain the pain

*Criteria fulfilled for the last 3 months with symptom onset

at least 6 months before diagnosis

\section{Rationale for Changes From Previous Criteria}

Studies determining the reliability of these criteria in identifying a homogeneous population are lacking, and subjects with various different explanations for pain (in particular, chronic pain attributed to pelvic viscera) may be represented. ${ }^{9}$ A lack of relationship of pain in FAPS with defecation separates this diagnosis from the functional bowel disorders, but the distinction from IBS has acknowledged difficulties and is not clearly based on scientific evidence. ${ }^{10}$ The requirements for some loss of daily functioning and that pain is not feigned are derived from the diagnostic criteria for somatization disorder and undifferentiated somatoform disorder. ${ }^{2}$ Qualifiers in the criteria (eg, "occasional" and "some") remain subjectively defined. Although discussed in the context of this article as a functional gastrointestinal disorder, FAPS also would qualify as a pain symptom contributing toward these diagnoses in psychiatric nosology.

\section{Clinical Evaluation}

A host of disorders can produce chronic abdominal pain, and the clinician should be aware of the extended differential diagnosis. ${ }^{11}$ Algorithms to diagnose and treat FAPS are empirical because objective scientific evidence to support a singular approach does not exist. It is suggested that evaluation consist of a clinical/psycho-
Table 2. Symptom-Related Behaviors Often Seen in Patients With FAPS

Expressing pain of varying intensity through verbal and nonverbal methods, may diminish when the patient is engaged in distracting activities, but increase when discussing a psychologically distressing issue or during examination

Urgent reporting of intense symptoms disproportionate to available clinical and laboratory data (eg, always rating the pain as "10" on a scale from 1 to 10 )

Minimizing or denying a role for psychosocial contributors, or of evident anxiety or depression, or attributing them to the presence of the pain rather than to understandable life circumstances

Requesting diagnostic studies or even exploratory surgery to validate the condition as "organic"

Focusing attention on complete relief of symptoms rather than adaptation to a chronic disorder

Seeking health care frequently

Taking limited personal responsibility for self-management, while placing high expectations on the physician to achieve symptom relief

Making requests for narcotic analgesics when other treatment options have been implemented

social assessment, observation of symptom reporting behaviors (Table 2), and a detailed physical examination. By answering a few questions, the physician effectively can appraise the clinical features of FAPS, identify the key psychosocial contributions to the disorder, and increase confidence in the diagnosis (Table 3). ${ }^{11}$

Typically, FAPS patients describe abdominal pain in emotional terms, ${ }^{12}$ as constant and not influenced by eating or defecation, as involving a large anatomic area rather than a precise location, as one of several other painful symptoms, and as a continuum of painful experiences beginning in childhood or recurring over time. For patients meeting diagnostic criteria for FAPS who exhibit a longstanding history of pain behaviors and certain psychosocial correlates, the clinical evaluation typically fails to disclose any other specific medical etiology to explain the illness. ${ }^{11}$ In the absence of alarm features common to the functional gastrointestinal disorders, conservative efforts should be taken to exclude other medical conditions in a cost-effective manner. Further detail regarding the clinical evaluation is beyond the

Table 3. Questions for Appraising Clinical Features of FAPS While Identifying Key Psychosocial Contributors

1. What is the patient's life history of illness?

2. Why is the patient presenting now for medical care?

3. Is there a history of traumatic life events?

4. What is the patient's understanding of the illness?

5. What is the impact of the pain on activities and quality of life?

6. Is there an associated psychiatric diagnosis?

7. What is the role of family or culture?

8 . What are the patient's psychosocial impairments and resources?

Adapted and reprinted with permission. ${ }^{11}$ 
scope of this article but can be found in prior reviews on the subject. ${ }^{1,11}$

\section{Physiological Features}

The observations that symptoms are reported as constant and unrelated to physiological events along with the common responsiveness of FAPS symptoms to low-dose tricyclic antidepressants point toward central neuropathic pain as a likely pathophysiological process. ${ }^{13}$ The common comorbidity of FAPS with psychiatric disorders (in particular, anxiety, depression, and somatization) and the fact that chronic abdominal pain is common in major depressive disorder ${ }^{14}$ suggest a prominent role of the central nervous system in altering pain modulation (cognitive or emotional). This does not exclude the possibility that, as in other neuropathic pain conditions, peripheral factors play a role in initiating or perpetuating this chronic pain state; scientific evidence to support such a mechanism, however, is not available. Descending pain modulation systems (opoidergic, serotonergic, and noradrenergic pathways) originate in distinct brainstem regions and modulate spinal cord excitability. It has been speculated that patients with various chronic pain syndromes, including fibromyalgia and FAPS, have compromised ability to activate such endogenous pain inhibition systems s $^{15,16}$ or exhibit an imbalance between facilitatory and inhibitory systems. Recent studies performed by using functional brain-imaging techniques identify interactions between prefrontal cortical regions, limbic regions, and brainstem regions that could provide the neurobiological substrate for the influence of cognitive factors on symptom perception in FAPS. ${ }^{17,18}$ Belief systems and coping styles characteristically seen in FAPS patients are consistent with the possibility of altered influences of cortical networks (including prefrontal and parietal cortical regions) on limbic and pain modulation circuits. ${ }^{19}$

\section{Psychological Features}

FAPS shows a close relationship with a variety of psychiatric and psychological conditions. Clinical evidence suggests that there is a strong association of aversive early life events and certain types of psychosocial stressors with increased pain reports among patients with functional gastrointestinal disorders. ${ }^{20,21}$ The combination of genetic factors, vulnerability factors, and adult stress may determine in part the effectiveness of endogenous pain modulation systems and thereby influence development of FAPS. Population- and patient-based studies have confirmed the significant association between chronic abdominal pain and affective disorders, especially anxiety and depression. ${ }^{22}$ Symptom-specific anxiety has been proposed recently as having a more direct influence on pain than general anxiety, ${ }^{23}$ and this construct also has been investigated in functional gastrointestinal disorders including abdominal pain. ${ }^{24}$ FAPS may be seen with other somatoform disorders (eg, somatization disorder, conversion disorder, and hypochondriasis). ${ }^{2}$ In a study of somatization disorder identified in a primary-care population, abdominal pain was present in $30 \%$ of subjects and was the third most frequent somatic symptom (after headache and back pain). ${ }^{25}$

Pain beliefs and coping strategies are important in chronic pain and somatoform disorders and are significant predictors of quality of life impairment and treatment response. ${ }^{26}$ Patients may exhibit ineffective coping strategies (eg, "catastrophizing") or have poor social or family support. ${ }^{27-31}$ Unresolved losses, including onset or exacerbation of symptoms after the death of a parent or spouse, personally meaningful surgery (eg, hysterectomy and ostomy), or interference with the outcome of a pregnancy (abortion, stillbirth), are common in FAPS. ${ }^{12,32}$ Histories of sexual and physical abuse are prevalent, ${ }^{33,34}$ but elevated rates are not specific for this diagnosis. These histories predict poorer health status, ${ }^{35}$ medical refractoriness, increased diagnostic and therapeutic procedures, and more frequent health care visits. ${ }^{33}$ Such trauma may increase awareness of bodily sensations, although visceral pain thresholds are not reduced. ${ }^{36,37}$

\section{Treatment}

In contrast to IBS, treatment recommendations for patients with FAPS are empirical and not based on results from well-designed clinical trials. The accepted basis for clinical management of FAPS relies on establishing an effective patient-physician relationship, following a general treatment approach, and offering more specific management that often encompasses a combination of treatment options. ${ }^{38-40}$ Factors that contribute to an effective patient-physician relationship ${ }^{11,39,40}$ include empathy toward the patient, ${ }^{41,42}$ patient education, validation of the illness, reassurance, treatment negotiation, and establishment of reasonable limits in time and effort. Before implementing specific forms of therapy (eg, antidepressants and anticonvulsants), the following general aspects of care should be considered: setting of treatment goals, helping the patient take responsibility, basing treatment on symptom severity and the degree of disability, and referring to a mental health care professional or, if available, to a multidisciplinary pain treatment center in selected patients, particularly those with refractory symptoms. Unfortunately, establishing a diagnosis, an effective patient-physician relationship, and a general treatment plan often is overlooked. Lack of confident 
diagnosis, nontherapeutic physician attitudes, excessive testing and treatment (including unnecessary surgery), and patient cognitions often contribute to a cycle of ineffective, costly management. ${ }^{43}$

Pharmacological therapies. Antidepressants, particularly tricyclic antidepressants (TCAs) in low daily dosages, are helpful in treating chronic pain and other painful functional gastrointestinal disorders, such as IBS, and may be useful for the treatment of FAPS for both direct pain management effects and antidepressant effects. ${ }^{44,45}$ However, evidence from controlled clinical trials for the effectiveness of antidepressants in FAPS or superiority of any 1 agent or antidepressant class in this disorder is not available. In other chronic pain conditions, trials with TCAs generally have been more successful than those using selective serotonin-reuptake inhibitors. ${ }^{46,47}$ Newer agents with combined serotonin and norepinephrine reuptake activity (SNRIs, such as venlafaxine and duloxetine) have recognized pain-reducing effects in some somatic pain conditions and may prove useful in FAPS. ${ }^{48}$ Both selective serotoninreuptake inhibitors and SNRIs may be useful in the patient with comorbid depression or anxiety. Most analgesics (eg, aspirin and nonsteroidal anti-inflammatory drugs) offer little benefit, possibly because their actions primarily are peripheral in location. Narcotic analgesics should be avoided because of the likelihood of addiction and possibility of narcotic bowel syndrome. ${ }^{49}$ Anticonvulsants have been evaluated in chronic pain syndromes, such as chronic neuropathic pain, as alternatives to TCAs with fewer side effects. The most studied have been gabapentin, carbamazepine, and lamotrigine. ${ }^{50}$ They have not been examined specifically in abdominal pain disorders or FAPS, although there is a rationale ${ }^{51,52}$ and evidence of efficacy in chronic pain management remains limited despite rather widespread use. ${ }^{53}$ These agents are relatively safe and nonhabituating, ${ }^{54}$ also may interrupt the cycle between pain and depression, ${ }^{55}$ and might prove beneficial as adjunctive agents in some refractory patients, although direct evidence is lacking. In summary, anecdotal reports and observed benefits of some compounds in other chronic pain conditions provide the basis for pharmacological treatment of FAPS not scientific evidence from controlled clinical trials.

Psychological therapy. No psychological treatment study specifically has targeted adult FAPS. However, studies in other painful functional gastrointestinal disorders and nongastrointestinal pain conditions suggest that psychological treatments would be beneficial. Interventions of potential benefit include cognitive behavioral therapy, ${ }^{44,56}$ dynamic or interpersonal psychotherapy, ${ }^{57,58}$ hypnotherapy, ${ }^{59}$ and stress management. Referral to pain treatment centers for multidisciplinary treatment programs may be the most efficient method of treating disability from refractory chronic pain. ${ }^{60} \mathrm{Al}-$ though the various psychological treatments described earlier have been shown to improve mood, coping, quality of life, and health care costs, they have less demonstrable impact on specific visceral or somatic symptoms, suggesting that their best use may be in combination with symptomatic treatment. ${ }^{44,61}$ Psychological treatment may be most accepted if presented as a parallel intervention with ongoing medical care, a means for managing pain, and an attempt to reduce psychological distress from the symptoms.

Complementary therapies. Complementary and alternative therapies, such as spinal manipulation, ${ }^{62,63}$ massage, ${ }^{64}$ and acupuncture ${ }^{65}$ commonly are used by patients with chronic pain disorders, including FAPS, although data supporting their use are limited. Few reports have described the use of transcutaneous electrical nerve stimulation in patients with FAPS, and uncontrolled results are indeterminant. ${ }^{66}$ Although uncontrolled studies suggest a significant diagnostic and therapeutic benefit of laparoscopy with intended adhesiolysis in patients with chronic abdominal pain tentatively attributed to adhesions from prior surgical procedures, ${ }^{67-69}$ the outcome may be placebo related and unsuspected diagnoses are rare. ${ }^{70} \mathrm{~A}$ blinded, randomized trial of 100 patients undergoing either laparoscopic adhesiolysis or diagnostic laparoscopy alone found no advantage to adhesiolysis. ${ }^{71}$ This study also reported a significant improvement in chronic abdominal pain over 6 months whether laparoscopy alone or laparoscopic adhesiolysis were performed, suggesting spontaneous improvement in these patients over time.

\section{Topics for Future Research}

FAPS remains an underinvestigated disorder with little evidence-based research appearing since the last edition of the Rome criteria. Evaluation of both diagnostic and treatment approaches for their effectiveness in clinical settings and studies of the long-term outcome of these approaches toward morbidity reduction are required. Specific areas of desired investigation include the following: (1) further characterization of patients with FAPS to augment the diagnostic criteria and improve their specificity; (2) better identification of the central neurophysiological processes involved in symptom production and effects of treatment on these processes; (3) clearer definition of investigative and management algorithms depending on presenting characteristics or by identification of clinical subgroups; (4) improved understanding of the relationship of somatization and somatization disorder to the presentation, management, and 
outcome of FAPS; (5) assessment of physician role in management of FAPS patients and evaluation of patientclinician interaction toward patient outcome; (6) additional studies of antidepressants in patients with FAPS with clarification of their optimal use; (7) investigation of augmentative therapies, including combination pharmacological interventions and mixed pharmacological/ nonpharmacological treatments; and (8) better identification of the roles of nonpharmacological treatments, including exercise and complementary/alternative therapies, in FAPS management.

\section{References}

1. Thompson WG, Longstreth G, Drossman DA, Heaton K, Irvine EJ, Muller-Lissner S. Functional bowel disorders and D. functional abdominal pain. In: Drossman DA, Corazziari E, Talley NJ, Thompson WG, Whitehead WE, eds. Rome II: The functional gastrointestinal disorders. Diagnosis, pathophysiology and treatment: A multinational consensus. Mclean, VA: Degnon Associates, 2000: 351-432.

2. American Psychiatric Association. Diagnostic and statistical manual of mental disorders-DSM-IV. Washington, DC: American Psychiatric Association, 1994.

3. Koloski NA, Talley NJ, Boyce PM. Epidemiology and health care seeking in the functional GI disorders: a population-based study. Am J Gastroenterol 2002;97:2290-2299.

4. Kwan AC, Bao TN, Chakkaphak S, Chang FY, Ke MY, Law NM, Leelakusolvong S, Luo JY, Manan C, Park HJ, Piyaniran W, Qureshi A, Long T, Xu GM, Xu L, Yuen H. Validation of Rome II criteria for functional gastrointestinal disorders by factor analysis of symptoms in Asian patient sample. J Gastroenterol Hepatol 2003;18:796-802.

5. Thompson WG, Heaton KW, Smyth GT, Smyth C. Irritable bowel syndrome in general practice: prevalence, characteristics, and referral. Gut 2000;46:78-82.

6. Drossman DA, Li Z, Andruzzi E, Temple RD, Talley NJ, Thompson WG, Whitehead WE, Janssens J, Funch-Jensen P, Corazziari E. U.S. householder survey of functional gastrointestinal disorders. Prevalence, sociodemography, and health impact. Dig Dis Sci 1993;38:1569-1580.

7. Bharucha $A E$, Camilleri M. Functional abdominal pain in the elderly. Gastroenterol Clin North Am 2001;30:517-529.

8. Maxton DG, Whorwell PJ. Use of medical resource and attitudes to health care of patients with chronic abdominal pain. $\mathrm{Br} \mathrm{J}$ Med Econ 1992;2:75-79.

9. Wong HY, Mayer EA. Gastrointestinal pain. In: McMahon S, Koltzenburg M, eds. Wall and Melzack textbook of pain. 5th ed. New York: Elsevier, 2005.

10. Guthrie EA, Creed FH, Whorwell PJ, Tomenson B. Outpatients with irritable bowel syndrome: a comparison of first time and chronic attenders. Gut 1992;33:361-311.

11. Drossman DA. Functional abdominal pain syndrome. Clin Gastroenterol Hepatol 2004;2:353-365.

12. Drossman DA. Patients with psychogenic abdominal pain: six years' observation in the medical setting. Am J Psychiatry 1982; 139:1549-1557.

13. Devor M. Neuropathic pain: what do we do with all these theories? Acta Anaesthesiol Scand 2001;45:1121-1127.

14. Ohayon MM, Schatzberg AF. Using chronic pain to predict depressive morbidity in the general population. Arch Gen Psychiatry 2003;60:39-47.
15. Edwards RR, Ness TJ, Weigent DA, Fillingim RB. Individual differences in diffuse noxious inhibitory controls (DNIC): association with clinical variables. Pain 2003;106:427-437.

16. Wilder-Smith $\mathrm{CH}$, Schindler D, Lovblad K, Redmond SM, Nirkko A. Brain functional magnetic resonance imaging of rectal pain and activation of endogenous inhibitory mechanisms in irritable bowel syndrome patient subgroups and healthy controls. Gut 2004;53:1595-1601.

17. Petrovic $P$, Ingvar $M$. Imaging cognitive modulation of pain processing. Pain 2002;95:1-5.

18. Lieberman MD, Jarcho JM, Berman S, Naliboff BD, Suyenobu BY, Mandelkern M, Mayer EA. The neural correlates of placebo ef fects: a disruption account. Neuroimage 2004;22:447-455.

19. Ringel $Y$, Drossman DA, Leserman J, Lin W, Liu H, Vogt B, Whitehead WE. Association of anterior cingulate cortex (ACG) activation with psychosocial distress and pain reports. Gastroenterology 2003;124:A97.

20. Mayer EA, Derbyshire S, Naliboff BD. Cerebral activation in irritable bowel syndrome. Gastroenterology 2000;119:1418-1420.

21. Mayer EA, Collins SM. Evolving pathophysiologic models of functional gastrointestinal disorders. Gastroenterology 2002;122: 2032-2048.

22. Bixo M, Sundstrom-Poromaa I, Bjorn I, Astrom M. Patients with psychiatric disorders in gynecologic practice. Am J Obstet Gy necol 2001;185:396-402.

23. McCracken LM, Zayfert C, Gross RT. The Pain Anxiety Symptoms Scale: Development and validation of a scale to measure fear of pain. Pain 1992:50:67-73.

24. Hazlett-Stevens H, Craske MG, Mayer EA, Chang L, Naliboff BD. Prevalence of irritable bowel syndrome among university students: the roles of worry, neuroticism, anxiety sensitivity and visceral anxiety. J Psychosom Res 2003;55:501-505.

25. El Rufaie OE, Al Sabosy MA, Bener A, Abuzeid MS. Somatized mental disorder among primary care Arab patients: I. Prevalence and clinical and sociodemographic characteristics. J Psychosom Res 1999;46:549-555.

26. Petrak F, Hardt J, Kappis B, Nickel R, Tiber EU. Determinants of health-related quality of life in patients with persistent somatoform pain disorder. Eur J Pain 2003;7:463-471.

27. Sarason IG, Sarason BR, Potter EH III, Antoni MH. Life events, social support, and illness. Psychosom Med 1985;47:156-163.

28. Jamison RN, Virts KL. The influence of family support on chronic pain. Behav Res Ther 1990;28:283-287.

29. Scarinci IC, McDonald-Haile J, Bradley LA, Richter JE. Altered pain perception and psychosocial features among women with gastrointestinal disorders and history of abuse: a preliminary model. Am J Med 1994;97:108-118.

30. Drossman DA, Whitehead WE, Toner BB, Diamant N, Hu YJ, Bangdiwala $\mathrm{SI}$, Jia $\mathrm{H}$. What determines severity among patients with painful functional bowel disorders? Am J Gastroenterol 2000;95:974-980.

31. Drossman DA, Leserman J, Li Z, Keefe F, Hu YJ, Toomey TC Effects of coping on health outcome among women with gastrointestinal disorders. Psychosom Med 2000;62:309-317.

32. Hislop IG. Childhood deprivation: an antecedent of the irritable bowel syndrome. Med J Aust 1979;1:372-374.

33. Drossman DA, Talley NJ, Leserman J, Olden KW, Barreiro MA. Sexual and physical abuse and gastrointestinal illness. Review and recommendations. Ann Intern Med 1995;123:782-794.

34. Wurtele SK, Kaplan GM, Keairnes M. Childhood sexual abuse among chronic pain patients. Clin J Pain 1990;6:110-113.

35. Drossman DA, Li Z, Leserman J, Toomey TC, Hu YJ. Health status by gastrointestinal diagnosis and abuse history. Gastroenterology 1996;110:999-1007.

36. Mayer EA, Gebhart GF. Basic and clinical aspects of visceral hyperalgesia. Gastroenterology 1994;107:271-293. 
37. Ringel $\mathrm{Y}$, Whitehead WE, Toner BB, Diamant NE, Hu Y, Jia H, Bangdiwala SI, Drossman DA. Sexual and physical abuse are not associated with rectal hypersensitivity in patients with irritable bowel syndrome. Gut 2004;53:838-842.

38. Drossman DA. The physician-patient relationship. In: Corazziari E, ed. Approach to the patient with chronic gastrointestinal disorders. Milan: Messaggi, 1999:133-139.

39. Drossman DA. Psychosocial factors in the care of patients with Gl disorders. In: Yamada T, Alpers DH, Kaplowitz N, Laine L, Owyang C, Powell DW, eds. Textbook of gastroenterology. 4th ed. Philadelphia: Lippincott, WIlliams \& Wilkins, 2003:620-637.

40. Chang L, Drossman DA. The psychosocial interview in the irritable bowel syndrome. Clin Perspect Gastroenterol 2002;5:336-341.

41. Zinn W. The empathic physician. Arch Intern Med 1993;153: 306-312.

42. Stewart M, Brown JB, Boon H, Galajda J, Meredith L, Sangster M. Evidence on patient-doctor communication. Cancer Prev Control 1999;3:25-30.

43. Longstreth GF, Drossman DA. Severe irritable bowel and functional abdominal pain syndromes: managing the patient and health care costs. Clin Gastroenterol Hepatol 2005;3:397-400.

44. Drossman DA, Toner BB, Whitehead WE, Diamant NE, Dalton CB, Duncan S, Emmott S, Proffitt V, Akman D, Frusciante K, Le T, Meyer K, Bradshaw B, Mikula K, Morris CB, Blackman CJ, Hu Y, Jia H, Li JZ, Koch GG, Bangdiwala SI. Cognitive-behavioral therapy versus education and desipramine versus placebo for moderate to severe functional bowel disorders. Gastroenterology 2003; 125:19-31.

45. Jackson JL, O'Malley PG, Tomkins G, Balden E, Santoro J, Kroenke K. Treatment of functional gastrointestinal disorders with antidepressant medications: a meta-analysis. Am J Med 2000;108:65-72.

46. Fishbain DA, Cutler RB, Rosomoff HL, Rosomoff RS. Do antidepressants have an analgesic effect in psychogenic pain and somatoform pain disorder? A meta-analysis. Psychosom Med 1998;60:503-509.

47. O'Malley PG, Jackson JL, Santoro J, Tomkins G, Balden E, Kroenke K. Antidepressant therapy for unexplained symptoms and symptom syndromes. J Fam Pract 1999;48:980-990.

48. Briley M. Clinical experience with dual action antidepressants in different chronic pain syndromes. Hum Psychopharmacol 2004; 19(S1):S21.

49. Sandgren JE, McPhee MS, Greenberger NJ. Narcotic bowel syndrome treated with clonidine. Resolution of abdominal pain and intestinal pseudo-obstruction. Ann Intern Med 1984;101:331334.

50. Guay DR. Adjunctive agents in the management of chronic pain. Pharmacotherapy 2001;21:1070-1081.

51. Bueno L, Fioramonti J, Garcia-Villar R. Pathobiology of visceral pain: Molecular mechanisms and therapeutic implications. III. Visceral afferent pathways: A source of new therapeutic targets for abdominal pain. Am J Physiol Gastrointest Liver Physiol 2000; 278:G670-676.

52. Holzer P. Gastrointestinal pain in functional bowel disorders: sensory neurons as novel drug targets. Expert Opin Ther Targets 2004;8:107-123.

53. Wiffen P, Collins S, McQuay H, Carroll D, Jadad A, Moore A. Anticonvulsant drugs for acute and chronic pain. Cochrane Database Syst Rev 2000;CD001133.

54. Hansen HC. Treatment of chronic pain with antiepileptic drugs: a new era. South Med J 1999;92:642-649.
55. Kudoh A, Ishihara H, Matsuki A. Effect of carbamazepine on pain scores of unipolar depressed patients with chronic pain: a trial of off-on-off-on design. Clin J Pain 1998;14:61-65.

56. Keefe FJ, Dunsmore J, Burnett R. Behavioral and cognitive-behavioral approaches to chronic pain: recent advances and future directions. J Consult Clin Psychol 1992;60:528-536.

57. Creed F, Fernandes L, Guthrie E, Palmer S, Ratcliffe J, Read N, Rigby C, Thompson D, Tomenson B. The cost-effectiveness of psychotherapy and paroxetine for severe irritable bowel syndrome. Gastroenterology 2003;124:303-317.

58. Guthrie E, Creed F, Dawson D, Tomenson B. A randomised controlled trial of psychotherapy in patients with refractory irritable bowel syndrome. Br J Psychiatry 1993;163:315-321.

59. Whorwell PJ, Prior A, Colgan SM. Hypnotherapy in severe irritable bowel syndrome: further experience. Gut 1987;28:423-425.

60. Kames LD, Rapkin AJ, Naliboff BD, Afifi S, Ferrer-Brechner T. Effectiveness of an interdisciplinary pain management program for the treatment of chronic pelvic pain. Pain 1990;41:41-46.

61. Heymann-Monnikes I, Arnold R, Florin I, Herda C, Melfsen S, Monnikes $\mathrm{H}$. The combination of medical treatment plus multicomponent behavioral therapy is superior to medical treatment alone in the therapy of irritable bowel syndrome. Am J Gastroenterol 2000;95:981-994.

62. Assendelft WJ, Morton SC, Yu EI, Suttorp MJ, Shekelle PG. Spinal manipulative therapy for low back pain. A meta-analysis of effectiveness relative to other therapies. Ann Intern Med 2003;138: 871-881.

63. Assendelft WJ, Morton SC, Yu EI, Suttorp MJ, Shekelle PG. Spinal manipulative therapy for low back pain. Cochrane Database Syst Rev 2004;CD000447.

64. Ernst E. Manual therapies for pain control: chiropractic and massage. Clin J Pain 2004;20:8-12.

65. Lee TL. Acupuncture and chronic pain management. Ann Acad Med Singapore 2000;29:17-21.

66. Sylvester K, Kendall GP, Lennard-Jones JE. Treatment of functional abdominal pain by transcutaneous electrical nerve stimulation. Br Med J (Clin Res Ed) 1986;293:481-482.

67. Onders RP, Mittendorf EA. Utility of laparoscopy in chronic abdominal pain. Surgery 2003;134:549-552.

68. Mueller MD, Tschudi J, Herrmann U, Klaiber C. An evaluation of laparoscopic adhesiolysis in patients with chronic abdominal pain. Surg Endosc 1995;9:802-804.

69. Shayani V, Siegert C, Favia P. The role of laparoscopic adhesiolysis in the treatment of patients with chronic abdominal pain or recurrent bowel obstruction. JSLS 2002;6:111-114.

70. Di Lorenzo N, Coscarella G, Lirosi F, Faraci L, Rossi P, Pietrantuono M, Manzelli A, Russo F, Gaspari AL. [Impact of laparoscopic surgery in the treatment of chronic abdominal pain syndrome]. Chir Ital 2002;54:367-378.

71. Swank DJ, Swank-Bordewijk SC, Hop WC, Van Erp WF, Janssen IM, Bonjer HJ, Jeekel J. Laparoscopic adhesiolysis in patients with chronic abdominal pain: a blinded randomised controlled multi-centre trial. Lancet 2003;361:1247-1251.

Received January 31, 2005. Accepted November 3, 2005.

Address requests for reprints to: Ray E. Clouse, MD, Division of Gastroenterology, Washington University School of Medicine, 660 South Euclid Avenue, Campus Box 8124, St Louis, Missouri 63110. e-mail: rclouse@im.wustl.edu; fax: (314) 454-5107. 